\title{
DIRECTIONS AND PERSPECTIVES OF EMOTIONAL INTELLIGENCE IN ORGANIZATIONS Mihaela ROCO*
}

\section{Abstract}

In the past 20 years research on Emotional Intelligence (EI) has increased exponentially, being made by scientists and experts from various fields of activity worldwide. EI research studies were oriented towards three main directions: 1) The development of conceptual models and related theories, 2) Construction and validation of tools / testing investigation and evaluation of EI and, 3) The development and validation of stimulation and development programs of EI in the areas of organizational, educational, medical, military, and more.

Peter Salovey, one of the parents of emotional intelligence, Invited Speaker at the 3rd International Congress on Emotional Intelligence (September, 2011), pointed out that one of the most valuable research directions of EI refers to its applications and its use at the workplace.

The current study includes three main parts: 1) History of the concept of EI and its contemporary approaches, 2) The results of extensive research on the usefulness and efficiency of EI in organizations (case studies), 3) stimulation and development programs in El's different fields (banking, educational, medical, business environment...).

Key words: classical and modern meanings of El's, Case studies on EI, the EI's development programs.

\section{Short historical considerations}

In defining intelligence, most psychologists focused mainly on cognitive aspects such as memory and problem solving. Some researchers have recognized early the importance of non-cognitive aspects. For instance, David Wechsler defined intelligence as "the total or global capacity of the individual to act intentionally towards achieving an objective, rational thinking, and to relate effectively with its environment."(1940). Since 1940 he referred to the "non-intellectual" elements, as well as intellectual ones, representing in his acceptance emotional factors, personal and social. In addition, Wechsler felt that non-intellectual skills are essential to predict the capacity to succeed in life. He appreciated: "The main question is whether non-intellectual factors, namely

* Mihaela ROCO is a university professor PhD at the Faculty of Psychology and Sciences of Education, University of Bucharest. E-mail: roco.mihaela@gmail.com 
affective and conative abilities, are admissible as factors of general intelligence. My statement was that such factors are not only admissible, but necessary. I tried to show that in addition to intellectual factors also exist factors, defined as non-intellectual, which determine intelligent behavior" (1940, p.444-445).

In the event that the above observations are correct, it follows that we can not expect to measure intelligence as long as our tests will not also include some measurements of nonintellectual factors. He wasn't the only researcher who observed that non-cognitive aspects are important in adaptation and can predict success. Robert Thomdike, for example, wrote about "social intelligence" in the "30s. Unfortunately, the work of these pioneers had no resonance or was overlooked until 1983, when Howard Gardner began to write about "Multiple Intelligences". He believed that "intrapersonal" and "interpersonal" intelligence are as important as the type of intelligence measured by IQ tests and related measures.

By the early ' 90 s, considered as a milestone in the launch of studies on emotional intelligence, there have been other attempts at defining the role of non-cognitive factors that help people to succeed both in life and work.

\section{Short contemporary considerations on EI}

In 1990, when D. Salovey and J.D. Mayer introduced the term emotional intelligence they knew previous work on non-cognitive aspects of intelligence. They described emotional intelligence as "a form of social intelligence that involves the ability to monitor their own feelings and emotions as well as others, to discriminate between them and use this information to guide one's thinking and action." P.Salovey and J.D.Mayer also initiated a research program designed to develop valid measurement of emotional intelligence.

In the early 1990s Daniel Goleman joumalist for the New York Times science problems, was interested in research in the field of brain and behavior. He studied psychology at Harvard, where he worked with David McClelland, who was part of a group of researchers concerned with the low degree the traditional cognitive intelligence tests predict success in life.

IQ itself is not a very good predictor of performance at work: Hunter estimated that IQ counts about $25 \%$ and Sternberg estimated that $10 \%$ could be a more realistic estimate.

The results of a longitudinal research, conducted over a period of 40 years, on a sample of 450 boys who grew up in Sommerville, Massachusetts, with different education levels, different IQ showed that they have performed at work or in their lifetime due to skills acquired in childhood, such as capacity to manage frustration, control emotions and relating with other people. 
A longitudinal study was conducted on a sample of 80 graduates of doctoral programs in the 1950 s at UC Berkeley (have been used: personality inventories, intelligence tests, semi-clinical interviews). Forty years later, when they were about seventy years, were again analyzed: estimates were made on their success based on resumes, evaluations by experts in their fields, etc. . It tumed out that social and emotional abilities were four times more important than IQ in determining professional success and prestige.

However, it would be absurd to suggest that cognitive abilities are irrelevant for success in work, life and implicit in scientific activity. A person needs a relatively high IQ to be admitted to a scientific program, such as the $\mathrm{PhD}$. Doctoral school performance have less to do with IQ differences and more have to deal with social and emotional factors. This applies in other occupations and professions. Should also have to keep in mind that non-cognitive and cognitive skills are very linked. In fact, there is research that suggests that emotional and social skills help improve cognitive function. Goleman D. in his research has analyzed a variety of data that highlighted the importance of social and emotional skills in personal success. Some of this research came from personality and social psychology, and others in the field of neuropsychology.

We therefore believe that emotional intelligence is a new field of research in certain aspects, emotional intelligence is not really new. In fact, is based on a long history of research and theories in social psychology and personality. But Goleman never claimed otherwise. In fact, one of its main points which he argued was that the abilities associated with emotional intelligence have been studied by psychologists for many years and there is an impressive body of research in continuous development, which suggests that these skills are important for success in many areas of life. In addition, given the pace of world growth and continuous organizational change, there is growing demand for resources increasing the cognitive, emotional and physical aspects of a person, that of an employee, and this special set of skills will become more important. And this is good news for organizational psychologists, because they are the best suited to help clients use emotional intelligence in order to improve both productivity and psychological well-being at work.

\section{The importance of emotional intelligence in organizations - Case studies}

The results of the selection process for the U.S. Air Force recruits showed that most high performing recruits obtained high scores for assertiveness skills, empathy, happiness and emotional awareness. U.S. Air Force has also realized that by using EI in the selection of recruits increased 
their ability to predict success. Immediate gain was a saving of 3 million dollars annually. These gains have resulted from the fact that the Government Accounting Office has provided a report to Congress that led to the request and recommendation of the Secretary of Defense that all armed forces to adopt this procedure for recruitment and selection (Cherniss, 1999, as cited. Richard Handley and Reuven Bar-On).

In a multinational consulting firm experienced partners were evaluated in terms of emotional intelligence competencies. Partners who scored above average at least 9 out of the 20 emotional competencies achieved $\$ 1.2$ million more profit than other partners - a 139\% incremental gain (Boyatzis, 1999).

A study effectuated on 300 top managers of 15 companies worldwide proved to be six competencies that distinguish the best from the average, respectively influence, team leadership, organizational awareness, self-esteem, desire for achievement and leadership (Spencer, LM, Jr., 1997).

In L'Oreal Company sales agents selected on the basis of emotional competence recorded higher sales than the sales agents selected on the basis of old selection procedure. Annually, the sales agents selected on the basis of emotional competence sold $\$ 91,370$ more than the others, increasing revenue by $\$ 2,558,360$. Also, sales persons selected based on emotional competence have registered a fluctuation with $63 \%$ lower than those selected in a traditional manner (Spencer \& Spencer, 1993, Spencer, McClelland, \& Kelner, 1997).

In a national insurance company, insurance agents who had low levels of emotional skills such as confidence, initiative, and empathy sold insurance policies worth $\$ 54,000$ average. Those who had high levels of emotional competence in at least 5 of the 8 key emotional competences sold an average of \$ 114,000 (Hay McBer Research and Innovation Group, 1997).

In a large beverage company, using standard methods to hire division directors, $50 \%$ left the company in a period of 2 years, primarily because of low performance. When they started selecting based on emotional competencies such as initiative, confidence and leadership, only $6 \%$ in 2 years left. Moreover, the directors selected based on emotional competencies have achieved performances situated in the first third considering salary bonuses for the performance of the divisions they led ( $87 \%$ were in the first third). Moreover, directors who were selected based on these skills have exceeded sales goals by $15 \%$ to $20 \%$. Those who had not a high degree of emotional competence registered 20\% less than the targets (McClelland, 1999).

Research conducted by the Center for Creative Leadership found that the first causes for the decline of executives involve deficits of emotional intelligence. The three who prevail are: difficulty in handling change, inability to work well in teams and poor interpersonal relationships.

After supervisors in a manufacturing plant conducted training on emotional competencies such as actively listening to employees, to belp in solving their own problems, downtime was reduced by $50 \%$, formal complaints 
were reduced from an average of 15 to 3 per year and the plant exceeded productivity goals by $\$ 250,000$ (Pesuric \& Byham, 1996). Likewise, in another manufacturing plant where supervisors received a similar training, production has increased by $17 \%$. This increase in production was not recorded in the group of supervisors who were not trained in the emotional competencies (Porras \& Anderson, 1981).

One of the foundations of emotional intelligence -correct selfevaluation- was associated with superior performance among several hundred managers from 12 different organizations (Boyatzis, 1982).

Another emotional competence, ability to manage stress, was correlated with successful of the head of chain store retail. The most successful store chiefs were those who knew how to manage their stress. Success was based on net profits, sales per square foot, sales per employee and per investment / inventory (Lusch \& Serpkeuci, 1990).

Optimism is another emotional competence that leads to increased productivity. New sales people from Med Life who obtained high scores on tests of "learned optimism" sold 37\% more life insurance in the first two years than the pessimists (Seligman, 1990).

At a national fumiture retailer, the sales agents selected based on emotional competencies have half the quitting rate recorded in first year of activity (Hay / McBer Research and Innovation Group, 1997).

A study conducted by the Egon Zehnder International Company, on 515 senior executives, showed that the ones who had high emotional competence are more likely to succeed than those who had high scores on IQ or relevant previous experience. In other words, emotional intelligence was a better predictor of success than other relevant experience or high IQ coefficient. This study included executives in Latin America, Germany, Japan, and the results were almost identical in all three cultures (Cherniss, 1999).

\section{Directions and perspectives of EI in organizations - development programs}

The spread and growing interest on emotional intelligence and its importance in organizations (Goleman, 1995) led to the development of programs designed to: work

- to educate people about the relevance of emotional intelligence at

- assess the strengths and weaknesses

- to provide a framework for developing and improving the ability to interact with others using emotional intelligence (Boyatzis, 1999) 
In the following we try to bring some evidence on the effectiveness of emotional intelligence programs and put into account the current efforts in this area.

\subsection{Program to obtain and increase motivation (Achievement Motivation Training)}

This training program was developed by McClelland and applied on numerous occasions. Several studies have been conducted to document its evaluation effectiveness. Training methods used include reading, discussion, stimulating, case studies and development of an action plan to be put into practice in a personal framework.

Evaluations showed that participants in the program demonstrated significant rate of promotion within their company, compared to the control group. In another study evaluating such a program that targeted a small group of entrepreneurs has proven to be effective in influencing business performance. Results of an analysis of the benefit per cost of this program sponsored by the government showed that the increase in revenues due to rising profitability of the businesses brought the targeted profitability. The cost / benefit after two years were 5 to 1 (Miron, 1979).

This program had the primary goal of obtaining competence and motivation increasing. It was developed by psychologist David McClelland from Harvard and colleagues at the Hay McBer. It was used in different settings with participants of various kinds, including corporate executives, entrepreneurs, businessmen from minority and women, business students in programs, police officers and social workers. It was used in several countries, being first used in 1963 for Indian businessmen. The training program was delivered in different ways, from one week to duration of a semester for students, involving 70 hours or more divided in 5 days. The designers of this program have conceptualized that involving seven points of input, of stimulation respectively. The first the way is of obtaining motivation to learn. The second is that participants understand their own characteristics and objectives. The third is to help individuals to obtain practice actions to achievements in business and other games. A fourth input for participants is to correlate the behaviors of obtaining achievements with their conduct, their selfimage and goals. The fifth goal of the program is developing for those involved their own personal plan of action. Finally, the program gives participants feedback regarding progress toward achieving and accomplishing goals.

As mentioned earlier, more research has been made toward evaluating this program and the results proved to be generally positive. 


\subsection{The program of support Granting of support ("The Caregiver Support Program" - CSP)}

Aims to increase social support and participation in decisions related to staff working in social services. This program is specifically designed to meet two objectives:

- To teach employees about support potential of systems in mobilizing support and skills development available to others at work;

- To teach employees about participatory approaches to problem solving and to develop skills in implementing these approaches in team meetings at work.

This program is structured according to social learning theory, which emphasizes modeling and practicing new behaviors. The content of this training includes providing support to participants in understanding the existence of already in place support networks, to strengthen these networks, to explore ways in which social support from others and may help to solve problems and reduce stress at work, as well as mapping their strengths and weaknesses in their own social network at work.

Participants learn to refine their interpersonal abilities associated with social exchange of support with others, to clarify their doubt, to offer constructive feedback and to ask the help of others (Heaney, CA, Price, RH, \& Rafferty, J., 1995).

This program was designed by the staff at the Michigan Prevention Research Center, being implemented extensively in Michigan. An important aspect of this program is that staff and managers are rained together. One member of staff and one manager from each agency participated in CSP sessions, aimed to train other staff then based on new skills and concepts they have learned.

CSP The program involved six training sessions. Each session lasted between 4 and 5 hours, being conducted by two trainers. The results of this program the evaluation showed that participants registered high levels of support supervised, high levels achieved in evaluation and feedback and have related more with their peers. To date have participated in over 2,000 social workers and the program continues.

\subsection{Recruitment and selection based on competence}

Using competency-based recruitment procedures in the selection of employees with high performance has become standard practice in many organizations. An example program is competency-based selection used by L'Oreal for hiring sales people. Behavioral event interview (Behavioral Event Interview-EIB) developed by Hay Mcber was customary in identifying key 
competencies critical to success in sales, most is of emotional and social nature. Sales people selected by this procedure have sold significantly more than those selected by the company's previous procedure. Annually, the sales agents selected on the basis of have competence sold $\$ 91,370$ more than the control group, while net income increased by $\$ 2,558,360$ (Spencer \& Spencer, 1993).

\subsection{Emotional competence training program (Emotional Competence Training Program)}

It is designed for managers and was developed at American Express Financial Advisors since 1992. A major objective of this to the program is to help managers become "emotional coaches" to direct subordinates. The training program is designed to sensitize managers on assessing the role of emotions in the workplace and develop a greater awareness of their emotional reactions and those of subordinates. They also learned how to communicate to subordinates in ways that help them manage their emotions more effectively. In addition, the program includes training in several areas of competence in emotional intelligence, namely self-awareness, self-regulation, empathy and social skills.

An evaluation study of this to the program conducted by the company suggests that participation in this program has helped increase sales revenue. Consultants whose managers participated in this training were compared with an equal number of consultants whose managers were not trained. Sales figures showed that subordinates whose managers were trained were able to grow the business by $18.1 \%$ compared with $16.2 \%$ of subordinates whose managers did not participate in the program (EI Consortium, cited. Smith).

\subsection{Executive Coaching}

Individual Coaching Program for efficiency in Personnel Decisions International (PDI) is an individualized program for top managers and middle managers. The participant went through a one day session toward evaluating, diagnosis and feedback, followed by a coaching phase, which involves about a day of raining per month for six months. The participant will receive 50 hours of intensive counseling. Specific behavioral objectives are developed for each individual. These objectives are defined in terms of behavior expected within the job. Objectives are unique to each person, based on the needs and the results obtained in the assessment and diagnosis, integrated in the organizational description provided by the participant. Scores are collected from for each the participant behavior, from the coach and from participant's supervisor prior to coaching. These scores are compared with scores obtained immediately after training and over six months after completion of the coaching program (Peterson, 1993). Evaluation results indicated all three scores prove of desirable 
for optimization coaching behaviors. Furthermore, these improvements were maintained over time. The study included more than 2,500 top managers and middle managers (Peterson, 1996). Executive coaching has become a method of great popularity in promoting emotional intelligence in organizations. One of the programs for which were conducted rigorous validations is developed by Peterson, Uranoviwitz and Hicks, 1996). It includes more than 4,000 people. Depending on the individual, coaching can have as their objective any of the skills associated with emotional intelligence, but typically refers to selfawareness, self management and social skills.

\subsection{Training program in human relations}

This program was designed to evaluate the effects on human relations of training focused on managerial efficiency. It includes 90 minutes per session, consisting of three phases, namely: first phase belongs to discussions on leaders, leadership, leadership styles and followers and the styles of leadership. The second phase is the largest dedicated to the exercises of experiential leaming component, such as self-scoring on scales, managerial separation exercises, analysis / reasoning, listening and interviewing exercises. The third phase is based on motivational theories.

Measurements were made pre and post training self-consciousness, sensitivity to others' needs and styles of leadership. Also, behavioral scores were collected from supervisors and subordinates. The evaluation was performed after 90 days and 18 months, respectively, after the completion of the program. This training has proven effective in changing attitudes and behaviors, and these changes were correlated with increased managerial efficiency. Managers who have attended these courses and have improved self-conscious, were more sensitive to the needs of others and were concerned about the development of mutual trust with their subordinates. Subordinates felt that relationships and communication with their managers has been optimized.

\subsection{Management interactions.}

Since Goldstein and Sorcher's research appeared, behavioral modeling has been used in educating and training supervisory staff in many different environments. Underlying method is Bandura's social leaming theory, which suggests that people learn through observation and then through imitating models. One example of this approach is that of the Programme of Modeling Interactions, developed and delivered by Development Dimensions International (DDI).

Interactions Management is a program designed to improve leadership skills in areas such as productivity, conflict management, performance 
optimization, delegation and overcoming resistance to change by providing positive role models of behavior applied in the work environment.

Participants learn and practice abilities that are demonstrated by videotaped models. Over 3 million managers have been trained in the program of management interactions and practical skills in different branches of industry, namely: Public Administration, banks, insurance, manufacturing, medical, etc. Today there are different versions of this program who were evaluated and proved effective in promoting social and emotional skills.

Development Dimensions International (DDI) deals with modeling interactions and includes five nodal elements: 1) Overview of the content and skills to be leamed identifying and the presentation of factual content about each subject, 2) Presentation of positive video material - participants observe the demonstrated abilities, 3) The practical exercising of the skills by each participant; 4) Feedback - participants receive feedback on the correct degree of use of these skills and 5) Application at work - the participants will discuss how to apply these skills in the workplace (Pesuric, 1996).

\subsection{LeaderLab}

Since 1991, Center for Creative Leadership launched a program called LeaderLab, which is destined to assist individuals in becoming effective leaders. This program emphasizes the development of emotional competencies, such as self-awareness, leadership, as objective as possible self-assessment, initiative and innovation, the desire to achieve, catalyst for change and competencies of team work (Young \& Dixon, 1996). LeaderLab is a leadership program dedicated to top and middle managers. This program is implemented over a period of six months. Participants are encouraged to implement an action plan developed during initial training sessions. A second period of training emphasizes on how to change and improve the initial action plans. The results of this assessment is based on data collected from participants and their work colleagues that attests to improve areas of self-awareness, social awareness, self and social skills of the participant after completion of the program.

\subsection{Self-management program for obtaining attendance at work.}

This program has been used effectively in different groups of workers from diverse backgrounds. In one study, employees (electricians, carpenters, painters) were trained one hour a week for 8 weeks in group sessions. During these sessions they were taught how to: determine their close and future objectives regarding their work, to write a behavioral contract with himself in the self-administration of punishments and rewards, To monitor in their present workplace, to manage their rewards, to think about potential problems that may 
arise in implementing their plan and come up with potential solutions. This program demonstrated the effectiveness of its own and attendance at work has increased.

Management training program in itself was originally developed and used by clinician psychologists. The premise from which it started was that individuals who need to change can achieve success more easily if they can control the process of change. Better than to have a psychologist who uses behavioral principles to make the change, you learn the principles that help beneficiaries to use them on their own. When people have control over their program of change, they feel more effective, so the change can be lasting, in comparison if they feel that others control the change. Self-management programs can have impact on a large number of emotional competencies, including: realistic self-assessment, self-confidence, self-control, conscientiousness and safety and the desire to achieve.

\subsection{JOBS Program}

The main objective of the JOBS program is to develop a series of abilities that lead to an efficient search of jobs and to unemployed people to build confidence. Short term goal is to strengthen the ability to resist demoralization to unemployed people and to persevere in the face of barriers and obstacles encountered. This program seeks to help the participants to maintain high levels of motivation, be more confident and effective in trying to find jobs and manage the interview and frustration associated with searching for jobs.

The program contributes to the development of more social competences and emotional, by which: self-awareness, the correct self assessment, self-confidence, adaptability, self-control, empathy, organizational awareness, influence, communication and relationship building.

The results of an evaluation of this program showed that participants found work before those in the control group. A post-program research undertaken has shown beneficial effects on monthly earnings employment level and changing jobs. One month after the intervention, participants earned on average with $\$ 178$ per month more than the control group. After four months this advantage of gains increased to $\$ 227$ per month and a half year after it increased by $\$ 239$ per month. JOBS program was developed by a group of psychologists in collaboration with the Center for Prevention and Research Michigan, the University of Michigan (the center was involved because another purpose of the program, namely the prevention of depression and other psychological problems associated with unemployment). If initially the program was implemented in Michigan, then it was adopted in other states in the United States and other countries. 


\subsection{Interpersonal effectiveness training program for medicine students}

Advanced medical technologies, together with changes in how health care is delivered, had both benefits elements and disadvantages. One of the drawbacks has been the continuously growing dissatisfaction of how the medical staff behaves with patients. The main objective of this program is to teach students to use interpersonal skills, increase the level of communication and empathy with patients. Many medical schools worldwide have now in their curriculum component parts of this program.

A version of this training consists of 10 sessions of 90 minutes, twice a week for five weeks. Each session is structured on a specific topic, e.g. diagnosis of a serious illness, family counseling and chronic disease. Assessment results have portrayed that the program improves empathy and communication skills of participants compared with control group.

Assessment results have also portrayed that students who have followed this program have demonstrated a significant and lasting growth of support behavior, compared with control group which showed a decrease in this behavior (Roter et all, 1998).

\subsection{Training program in interpersonal conflict management for Police}

Since the '60s, social researchers have begun to raise questions about how much are police officers involved in interpersonal conflicts. Research has indicated that many of the injuries that occur are caused by their intervention in interpersonal conflicts between individuals who know each other. Also, changes in many communities have prevented police-community relations and many people think there is a lack of interpersonal competencies in conflict management by the police. These trends have led to increase interest in teaching the police to resolve interpersonal conflicts more effectively. Initially, these efforts have met considerable opposition from the traditional departments of military culture. However, in the process have been accepted and today you hardly find a city police department that has not used such training.

Many police agencies have implemented programs designed to improve the ability of guards to manage interpersonal and social conflicts. Some of the pioneers of this program were those in New York City Housing Authority. Training procedures for this group included group discussions, case studies of real life interpersonal conflicts, role playing, reading, all of these the participants to improve ability to manage interpersonal conflicts by providing learning experiences that required active involvement for each participant. 
Currently there are many programs to increase the level of emotional intelligence professional for most areas.

Considering the materials provided suggesting how teachers can cultivate emotional intelligence in students, there was increased interest in the last decade to develop curricula designed to focus on these skills (Mayer \& Cobb, Salovey \& Sluyter, 1997). For example, in a curriculum to develop emotional intelligence in elementary school students, Schilling (1996) recommended elements of self-awareness, management / managing emotions, decision making, stress management, personal responsibility, empathy, communication, group dynamics and conflict resolution. It is obvious that emotional intelligence is an important factor in developing a whole range of socio-emotional abilities. As a result, many school intervention programs designed to promote emotional intelligence are classified in a more general way, namely Social and Emotional Learning programs (Social and Emotional Learning - SEL) (Cohen, 1999, Elias et al., 1997 ). In the U.S. there are over 300 curricula aiming to study the social and emotional leaming. There are intervention programs for developing emotional intelligence at work (Caruso, Mayer, \& Salovey, in press; Cherniss \& Goleman, 1998, Goleman, 1998). However, these programs are at an early stage of development compared to those proposed in education for students. A promising approach to of emotional intelligence at work (in organization) is designed in the Weatherhead MBA program at Case Western Reserve University, where training on social and emotional competencies are incorporated into the curriculum for future business leaders (Boyatzis, Cowen , \& Kolb, 1995). Although not explicitly focused on their own, MBA students have the opportunity to meet experiences designed to foster initiative, flexibility, desire for achievement, empathy, confidence, persuasion, networking, self and group management. Communication and emotional skills are also incorporated rapidly in educating doctors (Kramer, Ber, \& Moores, 1989), as well as in life skills development (Williams \& Redford, 1997), thus becoming the key competences in personal, interpersonal and professional developing.

At the Third International Congress of Emotional Intelligence (8-9 September, 2011, Croatia) the role and place of emotional intelligence at work has constituted one of the main research directions presented, grouped into the following sections: EI at the workplace, in educational and academic setting, EI and personality qualities, EI, health and well-being. 


\section{Selective Reference}

1. BOYATZIS, R.E. (1999). From a presentation to the Linkage Conference on Emotional Intelligence. Chicago, IL, September 27, 1999.

2. CHERNISS, C., GOLEMAN, D. (Eds., in press), Emotional competence in organizations.

3. FEIST, G.J., BARRON, F. (1996, June). Emotional intelligence and academic intelligence: in career and life success. Annual Convention of the APA, San Francisco, CA.

4. GARDNER, H. (1983). Frames of mind. Bantam Books. New York.

5. GOLEMAN, D. (1998). Working with emotional intelligence.Bantam Books. New York.

6. KOMAN, E.S., WOLFF, S.B. (2008). Emotional intelligence competencies in the team and team leader: A multi-level examination of the impact of emotional intelligence on team performance.27 (1), 55-75.

7. MAIER, J.D., SALOVEY, P., CARUSO, D.R. (2004). Emotional intelligence: theory findings, and implications. Psychological Inquriry, 15, 197. 215. Psychological Science 9 (5), 331-339.

8. MIRON, D., MCCLELLAND, D.C. (1979). The impact of achievement motivation training on small bussinesses.Califomia Management Review, 21(4), 13-28.

9. PETERSON, D.B., URANOWITZ, S.W., HICKS, M.D.(1996). Management coaching at work: current practices in fortune 250 companies. Paper presented at the Annual Conference of the APA, Toronto.

10.ROCO, M. (2001, 2004). Creativitate si inteligenta emotionala. Polirom. Iasi.

11.ROCO, M. (2011). 1) Emotional intelligence-one factor of creativity. 2) Professional success and emotional intelligence. Papers presented at III International Congress on Emotional Intelligence, 8, 9 and 10 September 2011, Croatia.

12.SALOVEY, P., MAYER, J.D. (1990). Emotional intelligence. Imagination. Imagination, Cognition and Personality. 9 (3), 185-211.

13.SALOVEY, P. (2011). Emotional intelligence: where are we now?. Paper presented at III International Congress on Emotional Intelligence, 8, 9, and 10 September 2011, Croatia.

14.STERNBERG, P. (1996). Successful intelligence. Simon \&Schuster. New York.

15.THORNDIKE, R.L., STEIN, S. (1937). An evaluation of the attempts to measure social intelligence. Psychological Bulletin, 34, 275-284.

16.WECHSLER, D. (1940). Nonintellective factors in general intelligence. Psychological Bulletin, 37, 444-445.

www. e-joumal-issues and recent developments in emotional intelligence 